\title{
Depression and self-concept in girls with perception of pubertal onset
}

\author{
Ji Hyeon Yang, MD', \\ Sang Woo Han, MD', \\ Chan Woo Yeom, MD², \\ Yong Jun Park ${ }^{3}$, \\ Wha Su Choi ${ }^{3}$, \\ Ji Young Seo, MD', \\ Young Jin Koo, MD²
}

Departments of Pediatrics ${ }^{1}$ and Psychiatry², Eulji General Hospital, Eulji University School of Medicine, Seoul, Department of Medicine ${ }^{3}$, Eulji University School of Medicine, Daejeon, Korea

\begin{abstract}
Purpose: Early pubertal timing in girls is associated with psychological and behavioral problems. This study aimed to evaluate the psychological features of girls who perceived breast development beginning by analyzing their depression levels and selfconcept.

Methods: From March 2007 to December 2012, 93 girls were enrolled and assigned to a pre-8 (younger than 8 years, $n=43$ ) or post- 8 ( 8 years and older, $n=50$ ) group according to the age at onset of perceived breast development, and their height, body weight, body mass index, bone age (BA), Tanner stage, and luteinizing hormone and follicle-stimulating hormone levels were examined. We investigated their psychological state with the Korean Children's Depression Inventory (CDI) and Piers-Harris Children's Self-Concept Scale (PHCSC) to evaluate depression levels and self-concept, respectively. Results: The pre-8 group had a significantly greater height standard deviation score, $(0.5 \pm 1.01$ vs. $0.11 \pm 0.86, P=0.048)$ and more advanced $B A(2.07 \pm 1.02$ years vs. $1.40 \pm 0.98$ years, $P=0.004$ ) compared to the post- 8 group. There were no statistically significant intergroup differences for the CDI and PHCSC scores; however, the pre-8 group scored higher than the post- 8 group in the physical appearance and attributes domain of the PHCSC (9.93 \pm 2.57 vs. $8.52 \pm 3.03, P=0.017)$.

Conclusion: The timing of perceived breast development among girls who thought puberty to begin did not affect depression levels and self-concept. There was no correlation between Tanner stage and depression levels and self-concept despite the perception of pubertal onset. The pre-8 group had a more positive view of their physical appearance than the post- 8 group.
\end{abstract}

Keywords: Puberty, Sexual development, Depression, Self concept

\section{Introduction}

The onset of secondary sexual characteristics before the age of 8 years in girls and 9 years in boys is defined as precocious puberty, whereas that between 8 and 10 years of age in girls and between 9 and 11 years of age in boys is referred to as early puberty ${ }^{1)}$. There is a global trend toward earlier puberty ${ }^{2,3)}$, especially among girls ${ }^{4)}$. Although the exact causes of the recently increasing incidence of accelerated pubertal onset are unknown, obesity, environmental hormones, and stress are assumed to be the causes of this trend.

Many studies have been conducted to investigate whether early maturing girls develop behavioral and psychological problems more frequently than normal maturing girls do. Girls with early puberty have been reported to develop negative self-image, and early menarche entails a high incidence of sexual experience, smoking, behavioral disorders, and psychological disorders $^{5-7)}$. Meanwhile, a study has suggested that during the growth spurt period triggered by pubertal onset, the accompanying advanced mental development leads to increased cognitive abilities and better school performance, which may be temporary rather than long term $^{8)}$

Tel: +82-2-970-8226

Fax: +82-2-970-8862

E-mail: pedseo@eulji.ac.kr 
Early pubertal development in girls is the most common cause of referral to our endocrinology clinic. Some girls may be classified as true precocious puberty, but concerns are frequent even if the pubertal development can be regarded as early or normal. Because there is nationwide increased concern about precocious puberty and pubertal development, it is important to evaluate psychobehavioral state of girls who perceived puberty beginning. However, only a few related studies have been conducted in South Korea at present. Hence, we aimed to analyze the psychologic state of girls who perceived puberty beginning and visited to our endocrinology clinic for concern about early pubertal development.

\section{Materials and methods}

\section{Subjects}

The study included 93 girls who perceived breast development beginning and visited for concern about early pubertal development at Eulji General Hospital from March 2007 to December 2012. We excluded those who had underlying endocrine disorders such as growth hormone (GH) deficiency, type 2 diabetes mellitus, hypothyroidism, and constitutional growth delay, and underlying psychiatric disorders such as Asperger syndrome.

\section{Methods}

The girls included in this study were assigned to groups according to whether they were younger than 8 years (pre- 8 group) or 8 years or older (post- 8 group) at the onset of perceived breast development. Self-rating of pubertal status were assessed with direct observation and 15 girls (16\%) were classified as Tanner stage 1, 47 girls (51\%) as Tanner stage 2, 28 girls (28\%) as Tanner stage 3, 3 girls (3\%) as Tanner stage 4 . At the first visit, the Korean Children's Depression Inventory (CDI) and PiersHarris Childrens Self-Concept Scale (PHCSC) were completed by the patients and their parents, whose parents agreed to participate in the study. Clinical features such as height, body weight, body mass index (BMI), bone age (BA), predicted adult height (PAH), basal luteinizing hormone (LH), basal folliclestimulating hormone (FSH), peak LH, peak FSH, and Tanner stage were measured and compared. Among the girls with more than Tanner stage 2, a Gonadotropin releasing hormone $(\mathrm{GnRH})$ stimulation test was performed in subjects with a BA advance of more than 1 year over the chronologic age (CA) and the basal LH level $\geq 0.07 \mathrm{IU} / \mathrm{L}$ or the basal estradiol level $\geq 10 \mathrm{pg} /$ $\mathrm{mL}$; GnRH agonist (GnRHa) treatment was initiated in case of the peak LH level $\geq 5 \mathrm{IU} / \mathrm{L}$. After 1-year of GnRHa treatment, in case that growth velocity was less than $4 \mathrm{~cm} / \mathrm{yr}$ or PAH was less than $155 \mathrm{~cm}$ and the patient and their parents agreed with GH therapy, combined GnRHa and GH treatment was initiated. We compared the patients' heights, weights, BMIs, BAs, PAHs, and Tanner stages again upon completion of follow-up. The study design was approved by the Institutional Review Board of the
Eulji Medical Center (Permission No. 13-48).

\section{Research tools}

1) Children's Depression Inventory

The CDI was developed by Kovacs and Beck to assess pediatric depression symptoms. It comprises 27 question items that can be assessed on a 3-point scale ( 0,1 and 2$)$ in a self-reporting format. The Korean CDI was developed by Cho and Lee" , and its reliability and validity have been tested. Total scores can range from 0 to 54 points; the higher the $\mathrm{CDI}$ score, the more severe the depression is rated; the results have consistently been in the range of severe depression ${ }^{10)}$. The mean score of Korean children is $14.72 \pm 7.13$, and depression can be suspected if the score exceeds 22 points.

2) Piers-Harris Children’s Self-Concept Scale

The PHCSC was developed by Piers and Harris to assess self-concept in children. Its reliability and validity in Korea were tested by Kim et al. ${ }^{11)}$. The PHCSC is a self-reporting questionnaire consisting of 80 yes/no items. The sum of the affirmative answers, with 1 point assigned to each, yields the final score. The higher the score, the more positive the respondent's self-image. The mean total score of Korean children is $51.71 \pm 13.33$. The PHCSC is composed of 6 domain scales, and the total number of domain scale items is the maximum score. The domain scales are as follows: behavioral adjustment (16 items), intellectual and school status (17 items), physical appearance and attributes (13 items), freedom from anxiety (14 items), popularity (12 items), happiness and satisfaction (10 items).

\section{Statistical analysis}

The test results are expressed as mean \pm standard deviation (SD). For the results yielded by the pre- 8 and post- 8 groups, continuous and categorical data were tested and analyzed using the Student $t$-test and chi-square test, respectively. For statistical analysis, we used SPSS ver. 12.0 (SPSS Inc., Chicago, IL,USA) and set the significance level at $P<0.05$.

\section{Results}

\section{Comparison of baseline clinical and endocrine findings}

The mean ages at perceived breast development in the pre8 and post 8 groups were $7.27 \pm 0.61$ and $8.71 \pm 0.61$ years, respectively. The height and height standard deviation score (SDS) of the pre-8 group were $128.6 \pm 6.91 \mathrm{~cm}$ and $0.5 \pm 1.01$, which was significantly higher than those of the post- 8 group $133.8 \pm 7.17 \mathrm{~cm}$ and $0.11 \pm 0.86(P=0.001$ and $P=0.048)$. The weight and weight SDS of the pre- 8 group were $28.4 \pm 4.98$ $\mathrm{kg}$ and $0.59 \pm 0.82$, respectively, and those of the post -8 group were $32.2 \pm 8.53 \mathrm{~kg}$ and $0.40 \pm 0.95$, indicating no significant 
difference. The BMI and BMI SDS of the pre- 8 group were $17.07 \pm 1.92 \mathrm{~kg} / \mathrm{m}^{2}$ and $0.47 \pm 0.82$, respectively, and those of the post- 8 group were $17.85 \pm 2.97 \mathrm{~kg} / \mathrm{m}^{2}$ and $0.47 \pm 1.10$, there was no significant difference. Midparent height of the pre- 8 group was $157.5 \pm 14.1 \mathrm{~cm}$ and that of the post- 8 group was $160.3 \pm 5.2$ $\mathrm{cm}$, showing no significant difference. BA advance of the pre8 group was $2.07 \pm 1.02$ years, while that of the post- 8 group was $1.40 \pm 0.98$ years, and there was a significant intergroup difference $(P=0.004)$. There were no significant differences in basal LH, basal FSH, peak LH, and peak FSH levels between the 2 groups. Among the patients and their parents who visited our clinic because of concern about early breast development, some patients were diagnosed fatty breasts and classified as Tanner stage 1 (Table 1).

\section{Comparison of posttherapy auxological data}

Among the pre-8 group, $81 \%(n=35)$ received GnRHa for $16.5 \pm 10.0$ months and $5 \%(n=2)$ received GnRHa plus $\mathrm{GH}$ for $34.2 \pm 2.5$ months. In the post- 8 group, $58 \%$ of subjects $(n=29)$ received GnRHa for $14.4 \pm 6.2$ months and $8 \%(n=4)$ received GnRHa plus GH for $25.7 \pm 3.3$ months. There were no posttherapy intergroup differences for the height, height SDS, the weight, weight SDS, the BMI, BMI SDS, and BA advance; meanwhile, the mean PAH of the pre- 8 group increased from the baseline value of $154.7 \pm 5.8 \mathrm{~cm}$ to $159.9 \pm 7.5 \mathrm{~cm}$ posttherapy and that of the post- 8 group increased from $157.4 \pm 8.5$ $\mathrm{cm}$ to $159.7 \pm 8.2 \mathrm{~cm}$, which amounted to increases of 5.2 and 2.3 $\mathrm{cm}$, respectively (Table 2 ).

\section{Comparison of $\mathrm{CDI}$ and $\mathrm{PHCSC}$ results}

The questionnaires were answered at the first visit when the patients were referred to our clinic for early breast development. The mean age at the first visit of the pre- 8 and post- 8 groups were $7.83 \pm 0.80$ years and $9.08 \pm 1.27$ years. Age difference between the timing of breast development $(7.27 \pm 0.61$ years and $8.71 \pm 0.61$ years) and the timing of answering the questionares was not great. The mean CDI scores of the pre- 8 and post- 8 groups were $3.8 \pm 4.2$ and $4.7 \pm 5.4$, respectively, and the mean PHCSC score was $38.6 \pm 8.97$ for the pre- 8 group and $35.9 \pm 6.77$ for the post- 8 group; there were no significant intergroup differences for depression level and self-concept score. Although girls perceived puberty beginning, there was no correlation between Tanner stage and depression level and self concept, either. Among the PHCSC subscales, there was a significant intergroup difference for physical appearance and attributes, with the pre- 8 and post- 8 groups scoring $9.93 \pm 2.57$ and $8.52 \pm 3.03$, respectively $(P=0.017)$ (Table 3 ).

\section{Discussion}

Puberty is a biologically driven developmental transition with complex secondary effects on emotional, social, and sexual development. In particular, children with early puberty may attain a poor final height due to premature growth acceleration

Table 1. Comparisons of clinical and endocrine profiles according to the age at pubertal onset

\begin{tabular}{|c|c|c|c|c|}
\hline Variable & Total $(n=93)$ & Onset age $<8$ yr $(n=43)$ & Onset age $\geq 8$ yr $(n=50)$ & $P$-value \\
\hline Age at pubertal onset (yr) & $8.05 \pm 0.95$ & $7.27 \pm 0.61$ & $8.71 \pm 0.61$ & 0.000 \\
\hline Height (cm) & $131.40 \pm 7.48$ & $128.60 \pm 6.91$ & $133.80 \pm 7.17$ & 0.001 \\
\hline Height SDS & $0.29 \pm 0.95$ & $0.50 \pm 1.01$ & $0.11 \pm 0.86$ & 0.048 \\
\hline Weight (kg) & $30.45 \pm 7.33$ & $28.40 \pm 4.98$ & $32.20 \pm 8.53$ & 0.090 \\
\hline Weight SDS & $0.49 \pm 0.89$ & $0.59 \pm 0.82$ & $0.40 \pm 0.95$ & 0.315 \\
\hline BMI $\left(\mathrm{kg} / \mathrm{m}^{2}\right)$ & $17.48 \pm 2.55$ & $17.07 \pm 1.92$ & $17.85 \pm 2.97$ & 0.138 \\
\hline BMI SDS & $0.47 \pm 0.97$ & $0.47 \pm 0.82$ & $0.47 \pm 1.10$ & 0.988 \\
\hline BA (yr) & $10.10 \pm 1.43$ & $9.86 \pm 1.27$ & $10.33 \pm 1.54$ & 0.121 \\
\hline $\mathrm{BA}-\mathrm{CA}(\mathrm{yr})$ & $1.66 \pm 1.22$ & $2.07 \pm 1.02$ & $1.40 \pm 0.98$ & 0.004 \\
\hline $\mathrm{MPH}(\mathrm{cm})$ & $159.0 \pm 10.2$ & $157.5 \pm 14.1$ & $160.3 \pm 5.2$ & 0.200 \\
\hline $\mathrm{PAH}(\mathrm{cm})$ & $156.2 \pm 7.4$ & $154.7 \pm 5.8$ & $157.4 \pm 8.5$ & 0.740 \\
\hline Basal LH (IU/L) & $0.46 \pm 1.02$ & $0.39 \pm 0.93$ & $0.54 . \pm 1.11$ & 0.499 \\
\hline Basal FSH (IU/L) & $2.67 \pm 1.37$ & $2.65 \pm 1.42$ & $2.69 \pm 1.33$ & 0.892 \\
\hline Peak LH (IU/L) & $12.63 \pm 14.66$ & $11.78 \pm 11.01$ & $13.45 \pm 17.62$ & 0.625 \\
\hline Peak FSH (IU/L) & $16.29 \pm 6.68$ & $16.71 \pm 6.48$ & $15.87 \pm 6.93$ & 0.592 \\
\hline Tanner stage (\%) & & & & $0.113^{b)}$ \\
\hline $1^{\text {a) }}$ & 16 & 12 & 19 & \\
\hline 2 & 51 & 57 & 45 & \\
\hline 3 & 30 & 29 & 32 & \\
\hline 4 & 3 & 2 & 4 & \\
\hline
\end{tabular}

Values are presented as mean \pm standard deviation.

SDS, standard deviation score; BMI, body mass index; BA, bone age; CA, chronologic age; MPH, midparent height; PAH, predicted adult height; LH, luteinizing hormone; FSH, follicle stimulating hormone.

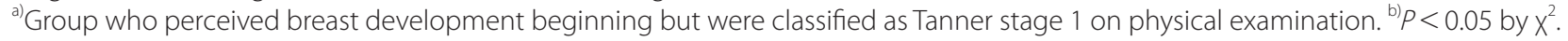


Table 2. Comparisions of post-therapy auxological data

\begin{tabular}{|c|c|c|c|}
\hline Variable & Onset age $<8$ yr $(n=37)$ & Onset age $\geq 8$ yr $(n=33)$ & $P$-value \\
\hline Height (cm) & $140.18 \pm 6.77$ & $141.47 \pm 7.33$ & 0.421 \\
\hline Height SDS & $0.44 \pm 0.92$ & $0.22 \pm 0.91$ & 0.292 \\
\hline Weight (kg) & $36.30 \pm 6.20$ & $37.80 \pm 8.26$ & 0.367 \\
\hline Weight SDS & $0.60 \pm 0.82$ & $0.50 \pm 0.95$ & 0.596 \\
\hline BMI $\left(\mathrm{kg} / \mathrm{m}^{2}\right)$ & $18.35 \pm 2.18$ & $18.71 \pm 2.64$ & 0.507 \\
\hline BMI SDS & $0.54 \pm 0.86$ & $0.56 \pm 0.97$ & 0.596 \\
\hline $\mathrm{BA}(\mathrm{yr})$ & $11.07 \pm 1.25$ & $11.23 \pm 1.19$ & 0.121 \\
\hline BA-CA (yr) & $1.10 \pm 1.06$ & $0.77 \pm 0.82$ & 0.153 \\
\hline $\mathrm{PAH}(\mathrm{cm})$ & $159.9 \pm 7.5$ & $159.7 \pm 8.2$ & 0.890 \\
\hline Tanner stage (\%) & & & $0.481^{\mathrm{a})}$ \\
\hline 1 & 45 & 55 & \\
\hline 2 & 13 & 10 & \\
\hline 3 & 33 & 26 & \\
\hline 4 & 10 & 10 & \\
\hline Treatment modality) (\%) & & & $0.087^{\mathrm{a})}$ \\
\hline 1 & 14 & 34 & \\
\hline 2 & 81 & 58 & \\
\hline 3 & 5 & 8 & \\
\hline Follow-up period (mo) & $24.45 \pm 12.21$ & $18.59 \pm 10.40$ & 0.024 \\
\hline
\end{tabular}

Values are presented as mean \pm standard deviation.

SDS, standard deviation score; BMI, body mass index; BA, bone age; CA, chronologic age; PAH, predicted adult height.

${ }^{a)} P<0.05$ by $X^{2}$. b) 1 , observation; 2 , Gonadotropin releasing hormone agonist; 3, Gonadotropin releasing hormone agonist and growth hormone.

Table 3. Comparisons of CDI and PHCSC results

\begin{tabular}{lcccc}
\hline Variable & Total $(n=93)$ & Onset age $<8$ yr $(n=43)$ & Onset age $\geq 8$ yr $(n=50)$ & $P$-value \\
\hline Age at first visit $(y r)$ & $8.50 \pm 1.24$ & $7.83 \pm 0.80$ & $9.08 \pm 1.27$ & 0.000 \\
CDI & $4.37 \pm 4.89$ & $3.8 \pm 4.2$ & $4.7 \pm 5.4$ & 0.179 \\
PHCSC & $37.10 \pm 7.93$ & $38.60 \pm 8.97$ & $35.90 \pm 6.77$ & 0.110 \\
Behavioral adjustment & $13.40 \pm 2.27$ & $13.50 \pm 2.27$ & $13.30 \pm 2.27$ & 0.626 \\
Intellectual and school status & $13.20 \pm 3.43$ & $13.80 \pm 2.72$ & $12.70 \pm 3.90$ & 0.142 \\
Physical appearance attributes & $9.20 \pm 2.90$ & $9.93 \pm 2.57$ & $8.52 \pm 3.03$ & 0.017 \\
Freedom from anxiety & $10.50 \pm 2.72$ & $10.80 \pm 2.89$ & $10.30 \pm 2.58$ & 0.416 \\
Popularity & $9.30 \pm 2.37$ & $9.50 \pm 2.15$ & $9.2 \pm 2.6$ & 0.445 \\
Happiness and satisfaction & $7.45 \pm 1.57$ & $7.70 \pm 1.38$ & $7.20 \pm 1.69$ & 0.091 \\
\hline Var
\end{tabular}

Values are presented as mean \pm standard deviation.

CDI, Children's Depression Inventory; PHCSC, Piers-Harris Children'S Self-Concept Scale.

and epiphyseal fusion induced by the pubertal increase in sex steroid hormone levels. Early maturing girls experience physical differences from their peers and their age of menarche is lower, which are associated with higher incidence rates of distorted self-image, depression, substance abuse, early sexual experience, pregnancy, and behavioral disorders ${ }^{12,13)}$. The majority of studies assessed pubertal timing by the age at menarche ${ }^{7,14)}$, but only a few studies have investigated the psychological aspects of early maturing girls who begin to develop breast. The present study was conducted to fill this gap in the lack of research. Our results revealed that the pre-8 group had significantly more advanced BAs than their CAs and a significantly higher height SDS than the post-8 group, indicating more accelerated progression of puberty.

We used the CDI, which was adapted from the Beck Depres- sion Inventory (BDI), to evaluate depression levels between pre- 8 and post- 8 groups. Our findings revealed no significant intergroup difference in the mean CDI score, consistent with that of a study conducted with Korean girls of similar ages who were stratified into a precocious puberty group (mean age, $8.12 \pm 0.64$ years) and control group (mean age, $7.95 \pm 0.22$ years $)^{15)}$, where the authors analyzed their results using a Korean Child Behavior Checklist and reported no intergroup differences in internalizing problems, including depression. In contrast, a foreign study that performed similar comparative analyses using the $\mathrm{BDI}$, where pubertal timing was assessed by age at menarche, reported that early maturing girls had more frequent incidences of depression, which was associated with the early onset of sexual activities under peer pressure before they were emotionally ready for it ${ }^{16)}$. 
Among the existing self-concept scales, the PHCSC is considered the most suitable for clinical investigation and therapy planning because it contains the largest accumulation of empirical outcomes and provides defined subscales ${ }^{11}$. There were no significant differences between the total PHCSC scores of the pre- 8 and post- 8 groups

Although the CDI and the PHCSC was developed to evaluate psychological condition in children and adolescent, their reliability and validity of Korean version were tested for schoolaged normal children who ranged from 4 th to 6 th grade of elementary school 1990 and 1994, respectively. In this study, mean ages of the respondents were pre- 8 group, $7.83 \pm 0.80$ years and post -8 group, $9.08 \pm 1.27$ years, thereby it seems that the mean CDI and PHCSC scores in this study show difference compared to those of Korean children due to age difference and generation gap.

Meanwhile the pre- 8 group scored higher than the post8 group in the subscale Physical Appearance and Attributes of PHCSC. This may be attributed to the satisfaction of the pre- 8 group associated with the higher height SDS, and it can be assumed that the early stage of breast development did not immediately trigger negative self-images in the subjects. Furthermore, a previous study investigating the conception of perceived height in children with idiopathic short stature (ISS) reported age-dependent differences in conception, indicating that the pivotal age for the child's sense of tallness was 8.2 years for girls and 9.0 years for boys; prior to these ages, the children generally described themselves as tall, whereas once they cross these ages, they generally described themselves as short ${ }^{17)}$. This pattern is similar to the findings of our study. This change can be explained by the fact that children's understanding of intentionality develops at approximately 8 or 9 years of age ${ }^{17,18)}$ and an increased focus on body image begins to emerge at this age ${ }^{19)}$. Thus, it was further reported that at the age of approximately $8-9$ years, the child begins to become aware of personal height in relation to others, at which point, short stature begins to have a negative effect upon the child's quality of life $\mathrm{e}^{20)}$. In this light, the lower self-concept score related to Physical Appearance and Attributes of the post- 8 group can be interpreted as an age-dependent natural phenomenon arising from the change of conception.

Although many studies have reported that early maturation was associated with higher incidences of crime, substance abuse, social isolation, early sexual behavior, and psychological problems such as depression, anxiety, and behavioral problems ${ }^{6,8,16)}$, a recent study with a long-term follow-up reported that the effects of early pubertal timing on adolescent psychosocial problems were wide-ranging, but diminished by young adulthood ${ }^{5}$. Similar result was reported by a large-scale longitudinal study of 466 women born in 1955 in Sweden ${ }^{14)}$ and the follow-up performed at the ages of 27 and 43 years revealed that women with menarche before the age of 11 years attained a lower educational level due to early sexual experience leading to marriage and childbirths. Regarding somatic development, at the age of 43 years, women with early menarche were shorter and heavier, had worse physical fitness, and dieted more frequently compared to other women. However, there was no difference in the quality of life ${ }^{14)}$.

Growth problems concern not only current physical health and adaptation to the physical and social environment, but also what will happen in the future as a consequence of growth problems ${ }^{21)}$. In our study, the pre- 8 group had a more positive view of their appearance as compared with the post- 8 group, but the pre-therapy PAH of the pre- 8 group was shorter than that of the post- 8 group. As the tendency toward short stature in adult age is greater with an earlier onset of puberty, it is important to establish a PAH-based therapy plan. Although the results of GH therapy studies in ISS record an average gain in adult height of approximately $4-6 \mathrm{~cm}^{22-24)}$, their heights remain shorter than that of their peers. Moreover, the benefits of $\mathrm{GH}$ therapy are still unclear. Thus, a recent consensus document on GH treatment in children with ISS places emphasis on the measurement of quality of life outcomes that can be achieved via increasing height ${ }^{25}$. As it has been shown that the influence of short stature can be diminished through various factors such as education, individual personality, and family environment, it is challenging to evaluate quality of life in children with short stature. In Korea, posttherapy longitudinal study is considered necessary to investigate the psychological conditions of early pubertal children to determine whether therapy has contributed any improvement in quality of life.

A sequel to this study is necessary to address limitations such as the small sample size, absence of analysis of socioeconomic status likely to affect patients, and absence of CDI- and PHCSCrelated follow-up assessments to analyze the post-therapy states of depression and self-concept.

In conclusion, no significant differences were found in the depression levels and self-concept based on the timing of perceived breast development among girls who thought puberty had begun and worried about early pubertal development. There was no correlation between Tanner stage and depression levels and self concept. The pre- 8 group had a more positive view of their appearance than the post- 8 group, which we assume is agedependent natural behavior. The younger the age at puberty, the lower is the age of menarche and shorter is the PAH. In such cases, it is desirable to ensure early diagnosis and timely therapy.

\section{Conflict of interest}

No potential conflict of interest relevant to this article was reported.

\section{References}

1. Park MJ. Update in the etiology and treatment of sexual precocity. Korean J Pediatr 2006;49:718-25.

2. Park YJ, Moon CM, Yoo HJ. A study of factors influencing advanced puberty. Korean J Pediatr 2010;53:146-51.

3. Na JM, Lee YJ, Kim MS, Lee DY, Yeo CY, Kim CJ, et al. 
Causes of precocious puberty: Multicenter Study in Honam Area. J Korean Soc Pediatr Endocrinol 2009;14:30-7.

4. Kim JH, Shin CH, Lee SY. Observed trends for an earlier onset of puberty: when is the need for treatment indicated? J Korean Med Assoc 2009;52:1189-200.

5. Copeland W, Shanahan L, Miller S, Costello EJ, Angold A, Maughan B. Outcomes of early pubertal timing in young women: a prospective population-based study. Am J Psychiatry 2010;167:1218-25.

6. Michaud PA, Suris JC, Deppen A. Gender-related psychological and behavioural correlates of pubertal timing in a national sample of Swiss adolescents. Mol Cell Endocrinol 2006;254-255:172-8.

7. Kaltiala-Heino R, Marttunen M, Rantanen P, Rimpela M. Early puberty is associated with mental health problems in middle adolescence. Soc Sci Med 2003;57:1055-64.

8. Ehrhardt AA, Meyer-Bahlburg HF. Psychosocial aspects of precocious puberty. Horm Res 1994;41 Suppl 2:30-5.

9. Cho SC, Lee YS. Development of the Korean form of the Kovacs' Childrenn's Depression Inventory. J Korean Neuropsychiatr Assoc 1990;29:943-56.

10. Charman T. The stability of depressed mood in young adolescents: a school-based survey. J Affect Disord 1994;30:109-16.

11. Kim BR, Cho SC, Shin YO. Development of Korean form of Piers-Harris Children's Self-Concept Scale. J Korean Neuropsychiatr Assoc 1994;33:1351-69.

12. Mazur T, Clopper RR. Pubertal disorders: psychology and clinical management. Endocrinol Metab Clin North Am 1991;20:211-30.

13. Ehrhardt AA, Meyer-Bahlburg HF. Idiopathic precocious puberty in girls: long-term effects on adolescent behavior. Acta Endocrinol Suppl (Copenh) 1986;279:247-53.

14. Johansson T, Ritzen EM. Very long-term follow-up of girls with early and late menarche. Endocr Dev 2005;8:126-36.

15. Kim EY, Lee MI. Psychosocial aspects in girls with idiopathic precocious puberty. Psychiatry Investig 2012;9:25-8.

16. Kaltiala-Heino R, Kosunen E, Rimpela M. Pubertal timing, sexual behaviour and self-reported depression in middle adolescence. J Adolesc 2003;26:531-45

17. Mull MS, Evans EM. Did she mean to do it? Acquiring a folk theory of intentionality. J Exp Child Psychol 2010;107:207-28.

18. Koopman HM, Baars RM, Chaplin J, Zwinderman KH. Illness through the eyes of the child: the development of children's understanding of the causes of illness. Patient Educ Couns 2004;55:363-70.

19. McCabe MP, Ricciardelli LA, Salmon J. Evaluation of a prevention program to address body focus and negative affect among children. J Health Psychol 2006;11:589-98.

20. Chaplin JE, Kristrom B, Jonsson B, Halldin Stenlid M, Aronson AS, Dahlgren J, et al. When do short children realize they are short? Prepubertal short children's perception of height during 24 months of catch-up growth hormone treatment. Horm Res Paediatr 2012;77:241-9.

21. Chaplin JE. Growth-related quality of life. Horm Res Paediatr 2011;76 Suppl 3:51-2.

22. Finkelstein BS, Imperiale TF, Speroff T, Marrero U, Radcliffe DJ, Cuttler L. Effect of growth hormone therapy on height in children with idiopathic short stature: a meta-analysis. Arch Pediatr Adolesc Med 2002;156:230-40.

23. van Gool SA, Kamp GA, Visser-van Balen H, Mul D, Waelkens JJ, Jansen M, et al. Final height outcome after three years of growth hormone and gonadotropinreleasing hormone agonist treatment in short adolescents with relatively early puberty. J Clin Endocrinol Metab 2007;92:1402-8.

24. Saggese G, Cesaretti G, Barsanti S, Rossi A. Combination treatment with growth hormone and gonadotropinreleasing hormone analogs in short normal girls. J Pediatr 1995; 126:468-73.

25. Cohen P, Rogol AD, Deal CL, Saenger P, Reiter EO, Ross JL, et al. Consensus statement on the diagnosis and treatment of children with idiopathic short stature: a summary of the Growth Hormone Research Society, the Lawson Wilkins Pediatric Endocrine Society, and the European Society for Paediatric Endocrinology Workshop. J Clin Endocrinol Metab 2008;93:4210-7. 